\title{
III. Observations on the acetic and acetous acids
}

\section{Darracq}

To cite this article: C. Darracq (1802) III. Observations on the acetic and acetous acids, Philosophical Magazine Series 1, 13:49, 12-20, DOI: 10.1080/14786440208676082

To link to this article: http://dx.doi.org/10.1080/14786440208676082

$$
\text { 册 Published online: } 18 \text { May } 2009 .
$$

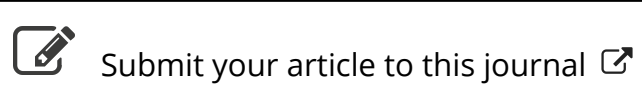

\footnotetext{
Џll Article views: 3
}

Q View related articles $\asymp$ 
rate the pafte under a fream of water, and to prepare a gluten entirely freed from any amylaceous principle. But before this object can be carried into execution, it will be neceffary that various trials thould be made by artifts to afcertain whether the glutinous folution has the properties requifite for painting, or at leaft for varnining.

Chemifts may, however, employ it in the mean time as luting. I mixed with fermented gluten diluted in alcohol a certain quantity of quicklime: ammonia and caloric were difengaged, and the mixture affumed a foft confiftence. With this pafte I luted feveral veffels, placed over them bands of linen clipped in the folution of gluten, and befprinkled them with quicklime : they foon adhered with fuch force that I think this luting preferable to that prepared with the whites of eggs.

It appears to me to refult from thefe exeperiments :

Ift, That frefh gluten is infoluble in alcohol.

$2 d$, That it becomes foluble when it has undergone acid fermentation.

3 d, That the alcoholic folution of gluten is precipitated by water.

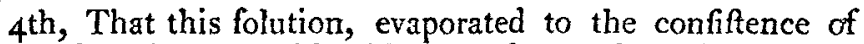
fyrup, furnithes a varnith which may be employed in the arts.

5 th, That fermented gluten diluted in alcohol becomes an excipient of colouring matters, and makes them adhere to the fmootheft bodies.

$6 \mathrm{th}$, That vegetable colouring fubftances combine with gluten better than others.

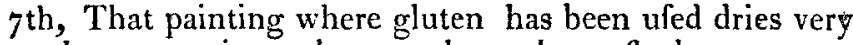
foon, has no noxious odour, and may be wafhed.

8 th, That a very ftrong and tenacious lating may be made with gluten and lime.

III. Objervations on the Acetic and Acetous Acids. By C. Darraca* .

THE numerous opinions of chemifts on the difference between the acetic and acetons acids have induced me to make a few refearches on the fubject. But before I give an account of my experiments I thall mention a few of thofe of the modern chemifts, and alfo the conclufions which they have drawn from them.

C. Adet read a memoir in the Inftitute, on the IIth Ther-

* From the Annales de Cbimie, No. 122.

midor, 
midor, year 6 , on the acetic acid, publinhed in the Annales de Cbimie of the fame year. By very interefting and wellperformed experiments $\mathrm{C}$. Adet endeavoured to prove that there did not exift two acids of vinegar, and he concluded from them, that the acetous acid is conftantly at the higheft degree of oxygenation; that it is confequently in the ftate of acetic acid; and, in the laft place, that the difference which exifts between the acetous and acetic acid feems to depend on the lefs quantity of water contained in the latter, and not on a greater proportion of oxygen, as before believed. I thall not defcribe his experiments, as they are tou numerous; I thall only obferve that they are very exact.

In the month of Brumaire, year $7, \mathrm{C}$. Chaptal pubiifhed his obfervations on the fame fubject *. By new experiusents he combats not thofe of $\mathrm{C}$. Adet, but the confequenees he has deduced from them. He bowever does not confider the acetic acid as more oxygenated than the acetous acid, but only as containing lefs carbon ; he mentions feveral experiments which feem in fupport his theory, and particularly the diftillation of acetite of copper. This celebrated chemift fays, that when this falt is diftilled the acetous acid is decarbonized; a part of this carbon combines itfelf with the oxygen of the oxide of the copper, and efcapes in carbonic acid; while the other remains in its natural ftate in the retort with the metallic oxide, and while the acetous acid, thus deprived of a portion of its carbon, paffes into the receiver in the ftate of acetic acid. A number of other experiments are quoted in fupport of this reafoning; but I thall not defcribe them as they are printed, I thall only defcribe thofe made by myfelf.

To afcertain whether the acetic acid was more oxygenated than the acetous acid, I repeated fome of C. Adet's experiments, which I found to be perfectly correet; but it would be ufelefs to defcribe them, fince all thofe chemifts acquainted with them are agrued in regard to the oxygenation of the acetic and acetous acids; but it will not be improper, perhaps, to mention fome new ones which feem to fupport this theory.

As the two acids in queftion differ a great deal by their concentration, I brought them before I employed them to the fame degree; and for this purpofe employed the fpecific gravity of pure acetous acid, which was 1.007 : on the other hand, I mixed with the acetic acid a fufficient quantity of diftilled water until its denfity was equal to that of 1.007 , or of acetous acid. In this ftate there is very little difference

* Anuales de Cbimie, vol, xxviii. p. $\mathbf{r}_{3}$. 
between thefe two acids, only that the acetic acid emits a very flight empyreumatic olour.

I took 2000 parts of acetous acid, which I put into a retort with 500 parts of nitric acid. The apparatus being properly difpofed for collecting the liquid and gafeous products, the mixture was carried to the ftate of ebullition, and continued till the 2000 parts nearly of the acetous acid employed were diftilled. No gas paffed during the operation, and the product, when examined, thowed no mark of alteration, its fpecific gravity being equal to that of the acid employed, that is to fay, 1.007 . When combined with oxide of lead, I obtained, by proper evaporation, a cryftallized falt, which was found to be common acetite of lead: it appears to be nearly certain that the acetous acid experienced no change during this operation; its odour was neither ftronger nor more penetrating than that of the acetous acid employed, and its favour was neither ftronger nor more pungent.

By a fecond experiment I again endeavoured to oxygenate, if poffible, the acetous acid. For this purpofe I prepared what was neceffary to obtain oxygenated muriatic acid gas, and the apparatus beirgy arranged the gas was received in a flafk containing acetous acid: after more than a fufficient quantity had paffed over, the apparatus was unluted, and the acid collected was carefully examined.

As the odour of the oxygenated muriatic acid conceals that of the acetous acid, the produet was placed in a capfule, and expofed to a gentle heat. When the greater part of the oxygenated muriatic acid had been defiroyed, the acetous acid exhibited no fenfible change; its favour only appeared to be fronger; on account, no doubt, of the muriatic acid which it contained. When combined, like that of the firft experiment, with oxide of lead, I obtained a needle-formed cryftallization of muriate of lead ; and then a fecond falt, perfectly fimilar to common acetite of lead, and to that of the firft experiment. I am therefore of opinion, efpecially when I call to mind the numerous experiments of $\mathrm{C}$. Adet, that we may affert that there do not exift two degrees of oxygenation in vinegar. Other experiments would be fuperfuous, fince, as I have already laid, chemifts are agreed on this point; but that on which opinions differ, is in regard to the different proportions of the carbon: the experiments I made on this fubject I thall here defcribe.

Exp. I. After having brought the acetic and acetous acids, as in the former cafe, to the fame degree of fpecific gravity, $I$ faturated a given quantity of pure and cryftallized carbonate 
of potath with the two acids. As it is very dificult to afcertain with certainty the true print of faturation, I thall not fpeak of the refpective quantities employed; they appeared to me to be nearly equal. . When I had evaporated thefe two falts to drynefs, they both prefented themfelves under the form of laminæ, of a favour equally pungent and hot, and, at laft, urinous and alkaline; in a word, no difference could be obferved between them.

For the prefent, I thall call the one acetite of potafs, and that made with acetic acid acetate. I took 576 parts of each of thefe falts, which had been evaporated and brought as far as poffible to the fame degree of deficcation, and put them into two glafs retorts. They were expofed in a furnace to an equal heat, and during the diftillation the fame phænomena were obferved. Some drops of a liquor flightly coloured, and of an acrid favour, paffed over into the two receivers. This liquor increafed in a fenfible manner till the end of the diftillation; and after expofure to a ftrong heat there remained in the two retorts a carbonaceous matter, which was treated with boiling water in order to remove by wafhing all the alkaline part mixed with the carbon. Being feparately filtered, there remained in the filters two light refiduums known to be charcoal. The two filters which contained them were placed in a ftove for 24 hours, and confequently were dried nearly in an equal degree. In this tate the two portions of charcoal being weighed, that of the acetite weighed $22 \frac{1}{2}$ parts, while that of the acetate weighed only 22 . It is feen by this refult that the difference is exceedingly fmall, and that there is reafon to believe that the degree of the deficcation of the refiduums, or of the falts employed, may be the caufe of the fmall quantity of charcoal which the acetite furnifhed more than the acetate.

Exp. II. I faturated cryftallized carbonate of foda with equal quantities of the acetous and acetic acid, and, by repeated evaporations, I obtained the two falts cryftallized in the fame manner: they exhibited ftriated prifms, among which I remarked fome hexaedral; their favour was equally pungent and bitter, and their colour white and brilliant.

Thefe two falts, well cryftallized, were dried in an equal degree between filtering paper in a place nightly heated, where they were left till the paper was no longer moiftened. $I$ then took, as in the former experiment, 576 parts of acetite and acetate of foda, and put them into two retorts: thefe two falts, expofed to a graduated heat, frrft became liquid: in proportion as I augmented the heat they became black, and there paffed over into the two receivers liquors flightly coloured, 
loured, in which floares a kind of oil, the quantities of which were apparently equal. After ftrongly urging the fire, there remained in the two retorts black refiduums, which I treated with boiling water as in the firft experiment. The charcoals remaining in the filters were dried in a ftove, and then weighed: that produced by the acetate of foda weighed eight parts, and that produced by the acetite eight parts and a half. Thefe two refiduums when examined were found to be charcoal, fimilar to that obtained by the acetite and acetate of potafh. This experiment, which on account of the cryftallization of the falts ought to be confidered as correct, fince the proportions of the conftituent parts of the falts were found to be the fame, explains what we have already announced, why the acetite of potah gave a little more charcoal than the acctate. There is reafon, no doubt, to believe that it arofe from the greater or lefs deficcation of the falts, and the manner in which they were burnt, fince in the fecond experiment I found not only the fame quantity of charcoal in the refiduum of the acetate of foda, but even a frnall quantity more than in the acetite.

Exp.III Being perfuaded, by the refults of thefe two experiments, that the acetous was not more carbonized than the acetic acid, I made as a new proof the following experiment: I put equal parts of fulphate of copper and acetite of lead, both cryftallized, pulverized, and mixed, into a'retort, which was placed in a furnace over an open fire, joined to the retort an adapter and a receiver, and to the latter a bent tube to collect the elaftic fluids. At a very gentle heat there paffed over a white liquid, which increafed without changing its colour: the fire being continued a confiderable time that I might obtain all the acetic acid, no other gas paffed over but a part of the air of the veffels; the heat was continued till the glafs retort began to enter into fufion, upon which it was taken from the fire. There remained a refiduum of a reddifh yellow colour, the weight of which was equal to two-thirds that of the mixture employed: the liquid obtained had a perfect refemblance to pure acetic acid, its weight was equal to a third of the quantities employed. A fimilar experiment is defcribed in the Annales de Cbrmie by C. Badolier; but its object, indeed, was different from that of the prefent one, it was publithed merely for the purpofe of giving a fimple and economical procefs for obtaining radical vinegar. The atlthor, however, obferves very juftly that no carbonic acid was difengaged, as was the cafe in my operation; nor did I obtain a fingle atom of acid gas. I endeavonred alfo to difcover whether any carbon remained in the refiduum; a rigorous examination 
examination fhowed that none exifted. This experiment with that above defcribed feems evidently to prove that acetous acid is not more carbonized than acetic acid; for it is certain that, if it eontained more, the excefs above that neceflary to conftitute the acetic acid produced would have remained in the refiduum.

However conclufive my experiments might be in my own opinion, I onght not to lofe fight of that of Chaptal, fince it is defcribed in the obfervations I have quoted. Having diftilled then, with a proper apparatus, 576 parts cryftallized acetite of copper, there paffed over into the receiver a white liquor, which was coloured by the progrefs of the diftillation, and which became green by the copper: this liquid was acetic acid. Before the diftillation there were difengaged 65 inches of a galeous fluid, which, when examined, wás found to be a mixture of carbonic acid gas and hydrogen gas : the refiduum, of a blackifh brown colour, being treated with muriatic acid, the latter diffolved the oxide of copper, and left a powder flightly black, which was collected on a filter : this black matter, when edulcorated, dried, and then fubjected to chemical examination, was found to be charcoal, the weight of which was 22 parts. As this refult was perfectly fimilar to that defcribed by the chemits, it was neceffary to exanine whether the confequences they deduced from it were very exact; for it may be alked, why the acetous acid was decarbonized under thefe circumftances alone, and not in that of which $I$ here give an account. Prefuming that I thould find a folution of this queftion by means of comparative experiments, I made the following:

I prepared acetate of copper by diffolving oxide of copper in acetic acid diluted with water, and by proper evaporation I obtained a falt cryftallized in octaedra. Of this falt, when dried to the fame degrce as the acetite of copper, I introduced 576 parts in a retort, and expofed it to heat: it exhibited exactly the fame phrenomena as the acetite. I obtained nearly equal quantities of hydrogen gas and carbonic acid. The liquid, when collested in the receiver, had the fame colour; when examined comparatively with that produced by the acctite, it was impofible to find any difference between them. The refiduum, of a blackith brown colour, was treated with muriatic acid, which diffolved the oxide of copper, and left a black matter, which floated on the liquid. - This matter, feparated by means of the filter, and dried on a ftove, being inbjected to analyfis, was found to be charcoal perfectly similar to that of the preceding experiment: it had abfoVor. XIII. No.4\%. 
lutely the fame weight as that produced by the diftillation of the acetite of copper; that is to fay, it weighed 22 parts.

From this refult it is evident that the charcoal obtained by diftilling acetite of copper does not arife from the acetous acid containing more than the acetic acid, fince the latter, when fubjected to the fame operation, gives an equal quantity. In my opinion, that produced in thefe operations does not arife from a portion of the acid decompofed, the quantities of which ought to vary according to the progrefs of the decompofition. Experience authorizes me to believe that the difference which may exilt between the two acids in quetion does not depend either on the proportions of the oxygen or of the charcoal. I fuperintended fome trials, not on the conftituent principles of vinegar, but on vinegar itfelf, and the kind of mucilage with which it is accompanied. Before I deforibe this labour I muft not forget to obferve that C. Chaptal furnithed me with the idea by his obfervations on the acetic and acetous acids. He fays on this fubject, that the acid of vinegar may be confidered as exitting primitively in a llate ahmoft faponaceous; which diminifhes its action, and weakens its properties.

After having afcertained, by fome experiments, the exiltence of this extrantive or mucilaginous principle, I endeavoured to feparate it. Diftillation as well as filtration were found to be imperfect means: my vinegar always contained mucilage : it remained nearly the fame. However, by combining it, after diffillation, with alkaline bafes, it depofited very little of that flaky matter called extraklive matter. Having not forgot, during thefe refearches, the opinion of C. Adet, who fays that the quantity of water might occafion the difference between the acetous and acetic acids, comparing the obfervations of thefe two chemifts, I made fome experiments, which appear to me to be interefting; but I Thall defcribe that only which appeared to me to be moft conclufive.

Entertaining the idea that there was no difierence between the acetous acid and the acetic, but a larger quantity of wat:r, and an extractive or mucilaginous matter, I endeavoured to find the proper means of leparating the former from it, and bringing it to the ftate of acetic acid. For this purpofe, I prepared muriate of lime, which I ftrongly calcined. Afier reducing it to powder, I put it into a tubulated retort, and poured over it common acetous acid with an apparatus proper for receiving the products. The retort, which was on a fandbath, boing expofed to a gentle heat, the matter inmediately 
entered into ebullition, on account of the heat produced by the calcareous falt in folidifying the major part of the water contained in the vinegar. During this diffillation there paffed over a clear liquor, which fell in ftrix on the fides of the adaptor, and which was collected in a receiver. This liquor totally changed in appearance; had a ftronger and more pungent favour than the acetous acid employed, and its odour was fharper and more penetrating: one might have taken it for diluted radical vinegar. This product, when fubjected to a fecond diftillation with dried muriate of lime, acquired a little more ftrength : after a third and a fourth rectification, a tranfparent liquor was obtained, of an odour and favour very fimilar to that of common acetic acid. During thefe rectifications, not an atom of charcoal was depolited. To afcertain whether the acid obtained, in lofing a great quantity of its water, had loft alfo the mucilaginous matter which accompanied it, I faturated a portion with cryftallized carbonate of potah : in vain did I add an excefs of this falt, for nothing was precipitated; whereas common acetous acid, by a fimilar faturation, precipitates a flaky matter, which is collected in the bottom of the veffel employed.

Though the ftrong and penetrating odour of the acetic acid obtained by the fimple means above defcribed was fufficient to induce me to conclude that it was really fimilar to that obtained from metallic acetites, I endeavoured to afcertain this fact by a new experiment. For that purpofe I took equal parts of this radical vinegar and of alcohol to try to make acetic ether: the attempt was not unfuccefsful; and, by Pelletier's procefs, I obtained an ether perfectly agreeable, and having an exact refenblance to the aretic ether found in laboratories. I nuft here obferve, in fpeaking of the acetic acid obtained by rectification alone with nuriate of lime, that it is far more agreeable than the actic acid produced, for example, by the diftillation of metallic acetites; and efpecially when they are diluted with water. The latter then affumes a difagrecable empyreumatic odour, and an oily favour, arifing from a portion of acctic acid which has been decompofed by the heat, and which has given birth to a kind of oil which the acid retains in combination. The otber, wn the contrary, paffes only to the ftate of common acid of linejar by preferving an agreeable pungency. Before any conclution can be drawn from the preceding refults, 1 muft not forget to mention an interefting fact remarked by C. Pontier. This able chemilt and mineralogitt, who difcovered the chromate of iron in France, fent, abont eight 
months ago, to $\mathrm{C}$. Vauquelin a flatk containing a liquor obtained by the diftillation of vinegar on a large fcale. As C. Pontier was not ignorant that the firft product of the diftillation of the acetuus acid is aqueous, he feparated it from that which followed. After uniting feveral phlegms of the fame kind, he was much aftonithed to find that thele phlegms had a very agreeable aromatic odour: having difcovered, by preliminary trials, the properties which gave this product a fimilarity to ethereal liquors, he rectified all the fuppofed phlegms, and by thefe means obtained a peculiar ether, which Vauquelin found to be acetic ether completely rectified.

From an identity fo friking in the experiments above defcribed, it is evident that there exifts no difference between the conftituent parts of the acetic and acetous acids; that the water, and mucilaginous or extractive matter, are the only two apparent differences obferved in thefe two acids; and, confequently, that there exifts only one acid of vinegar, which being at its maximum of oxygenation, ought, according to the chemical nomenclature, to be diftinguifhed by the name of acetic acid. In future, therefore, there will not exift two different kinds of falts, either by the combination of diftilled vinegar or of radical vinegar; they will hereafter be fo many products, the names of which mutt be the fame; and hence acetates will exift, and not acetites.

IV. Defription of a new Implement called a Cultivator. By Mr. William LESTER, of Nortbampton*.

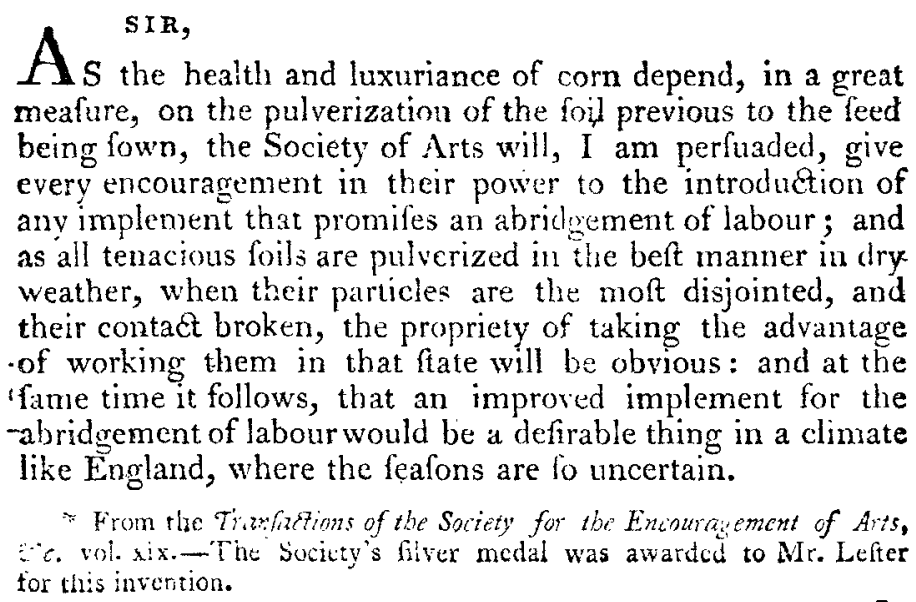

